\title{
Treatment of inflammatory bowel disease in children
}

\author{
D GRANT GALL, MD, FRCPC
}

\begin{abstract}
As no curative therapy exists, supportive measures play an important role in the management of patients with inflammatory bowel disease (IBD). Aminosalicylic acid (ASA) compounds and corticosteroids remain the mainstay of medical therapy. Aminosalicylates are recommended for therapy of mild to moderate active ulcerative colitis and for the maintenance of remission in ulcerative colitis. The role of 5-ASA preparations in Crohn's disease is less clear. In granulomatous colitis, 5-ASA therapy is recommended. With the development of new delivery systems, the role for 5-ASA in the treatment of small bowel Crohn's disease is under investigation. Prednisone remains the drug of choice in severe ulcerative colitis and active Crohn's disease. The role of immunosuppressive drugs in pediatric patients is unclear. Nutritional therapy has been an important advance in the treatment of children with Crohn's disease, especially those with growth failure. Nutritional therapy can consist of combined total parenteral and enteral nutrition or enteral nutrition alone. An initial period of total parenteral nutrition followed by a six to eight week course of enteral therapy with a semisynthetic diet has been shown to be effective in the management of patients with severe active disease and growth failure. Can J Gastroenterol 1990;4(7):404-406
\end{abstract}

Key Words: Crohn's disease, Inflammatory bowel disease, Ulcerative colitis

\section{Traitement des maladies inflammatoires de l'intestin chez l'enfant}

RESUME: Comme il n'existe aucun traitement curatif des maladies inflammatoires de l'intestin (MII), les mesures de soutien jouent un rôle important dans le soin des patients porteurs de MII. Les médicaments à base d'acide aminosalicylique (ASA) et les corticostéroïdes restent au coeur de la thérapie médicale. Les aminosalicylés sont recommandés dans les colites ulcéreuses (CU) d'activité faible à modérée et dans le maintien des rémissions de CU. Le rôle des préparations à base d'ASA dans la maladie de Crohn est moins évident. Dans la colite granulomateuse, le traitement par l'acide 5-aminosalicylique (5-ASA) est recommandé. Grâce à l'avènement de nouveaux systèmes de distribution, le rôle du 5-ASA dans le traitement de la maladie de Crohn du grêle est à l'étude. La prednisone reste le médicament de choix pour traiter les poussées évolutives de

Intestinal Disease Research Unit, University of Calgary, Calgary, Alberta

Correspondence and reprints: Dr DG Gall, Department of Pediatrics, Health Science Centre, 3330 Hospital Drive NW, Calgary, Alberta T2N 4N1
TFLAMMATORY BOWEL DISEASE (IBD) represents an important prob. lem in the pediatric age group. Ap proximately $15 \%$ of patients with ul. cerative colitis and $25 \%$ of patients with Crohn's disease present before the age of 18 years. In terms of gastrointes tinal disorders, more patients present each year with IBD than either cystic fibrosis or celiac disease. As seen in the adult population the incidence of Crohn's disease increased dramatically during the 1970s. At present the prevalence of Crohn's disease is twice that of ulcerative colitis. While many of the symptoms and complications seen in IBD are similar in adult and pediatric patients, there are distinct dif. ferences. Growth failure and delayed puberty are major problems in the pediatric age group, especially in patients with Crohn's disease.

\section{TREATMENT OF IBD}

Supportive measures: In the treatment of IBD, supportive measures are important, as no specific curative therapyex. ists. Patients and parents must be given insight into the nature of the illnessand an understanding of the prognosis in terms that they can accept without being terrified. Treatment will allow the vast majority of pediatric parients with IBD to lead a normal active lifestyle no different from their peers. $\mathrm{Oc}$. casionally patients and parents may re. 
la colite ulcéreuse et de la maladie de Crohn. Le rôle des immunosuppresseurs à usage pédiatrique est peu clair. La thérapie nutritionnelle constitue un progrès important dans le traitement des enfants atteints de maladie de Crohn, surtout ceux qui souffrent de retard de croissance. La thérapie nutritionnelle peut allier la nutrition parentérale totale (NPT) et la nutrition entérale ou recourir seulement à la nutrition entérale. Une période initiale de NPT suivie de six à huit semaines de thérapie entérale avec régime synthétique s'est avérée efficace dans le traitement des patients atteints de maladie active sévère et ceux qui souffrent d'un retard de croissance.

quire psychological support, but psychological intervention is rarely required. Adequate nutrition without restriction is important. There is no evidence that specific foods play a role in the etiology of these diseases or in the course of illness. Patients frequently require supplemental calories, vitamins and iron. Levels of activity should not be restricted except in acutely ill patients. The overall aim of treatment is to allow the child to live a lifestyle not substantially different than that of his or her peers.

\section{MEDICAL THERAPY}

The physician has a variety of therapeutic agents for the treatment of IBD. Atwinosalicylates and corticosteroids remain the mainstay of medical therapy $(4,5,7)$. However, the development of new formulations of aminosalicylates raises the hope for a broader therapeutic effectiveness of these agents in both ulcerative colitis and Crohn's disease.

Aminosalicylates: Until recently the treatment of IBD by aminosalicylates was limited to the use of sulphasalazine. Sulphasalazine was discovered to be effective in ulcerative colitis in the 1930s. The drug, initially developed for the treatment of rheumatoid arthritis, was found to be effective in the treatment of intestinal symptoms in a group of patients with arthritis associated with ulcerative colitis. Subsequent clinical trials confirmed the effectiveness of sulphasalazine in the treatment of patients with active ulcerative colitis and demonstrated its important role in maintenance therapy of ulcerative colitis patients. Understanding the pharmacology of sulphasalazine and the basis for adverse reactions led to the development of a new generation of agents, the aminosalicylates. Sulphasalazine by and large traverses the intestine intact until deconjugated into its sulfapyridine and 5-aminosalicylic acid (5-ASA) moieties by bacterial flora usually in the distal ileum and colon. The active moiety of the molecule is 5-ASA. Sulphasalazine simply acts as the delivery system. If 5-ASA is ingested separately it is largely absorbed in the proximal intestine, metabolized by the liver and excreted in the urine. In contrast, in the colon, 5-ASA is largely unabsorbed. This understanding of the pharmacology of sulphasalazine stimulated the search for new delivery systems for 5-ASA. Topical and oral preparations of 5-ASA have been shown to be as effective as sulphasalazine in the treatment of colitis and for maintenance therapy. Elimination of the sulpha moiety has resulted in improved tolerance. However, side effects related to 5-ASA do occur. A small proportion of patients will experience an exacerbation of colitis with 5-ASA, and watery diarrhea has been a problem with at least one oral formulation (6). Corticosteroids: Since their introduction in the 1940s, corticosteroids have been the drug of choice in moderate to severe ulcerative colitis and Crohn's disease. Oral corticosteroids have been shown to be effective in the treatment of both conditions. However, they do not have any apparent benefit in maintaining patients in remission. Topical steroids are also widely used and are effective in patients with distal colitis. Both oral and topical agents are associated with chronic adverse side effects. Recent investigations have identified a series of compounds that possess the anti-inflammatory properties of steroids and clinical efficacy but are free from the steroid-related side effects (8). The absence of toxicity is related to their mode of metabolism. They undergo extensive first pass metabolism by erythrocytes and the liver, resulting in metabolites with little or no biological activity. These agents have been shown to be effective when used topically in distal colitis. Oral formulations are presently under study.

Other agents: Metronidazole has been shown to be effective in the treatment of active Crohn's disease and related perianal disease. In children, however, the drug is rarely used because of limited therapeutic success and adverse side effects, including peripheral neuropathy and the potential for carcinogenesis (3). The role of immunosuppressive agents remains controversial. Azathioprine and 6-mercaptopurine have not been demonstrated to be particularly effective in acute Crohn's disease, but have been shown to have a steroid-sparing effect in chronic disease. These drugs are employed only as a last resort in pediatric patients who are refractory to steroids and aminosalicylates. A number of other medications including sodium cromoglycate, sucralfate and clonidine have been proposed as therapeutic agents for IBD, but their efficacy has not been established.

\section{NUTRITIONAL THERAPY}

Nutritional therapy has been shown to be effective in the treatment of Crohn's disease $(1,2)$, but has little to offer patients with ulcerative colitis except in terms of nutritional support. The indications for aggressive nutritional therapy in Crohn's disease include: failure of medical therapy; chronic smoldering disease unresponsive to prednisone therapy or requiring high dose long term therapy; and growth failure and delayed puberty. In the last group, nutritional therapy is the treatment of choice. Surgery in this type of patient should only be considered if nutritional therapy fails.

While growth failure can occur in chronic ulcerative colitis, the problem of chronic growth failure and delayed puberty is largely confined to patients with Crohn's disease. Growth failure in chronic IBD appears to be mainly due to inadequate caloric intake rather 
than underlying endocrine dysfunction, malabsorption or increased metabolic demands. Stimulation of growth can be achieved if adequate calories are provided, even in the face of ongoing disease activity. Both total parenteral nutrition and enteral feeding with either a refined or low residue diet appear to be effective in controlling disease activity and promoting growth. The aim is to achieve $120 \%$ of the recommended caloric daily intake. Unfortunately, while nutritional therapy is effective in inducing remission, prolonged remission after reintroduction of a normal diet is infrequent. However, long term remissions can be maintained if nutritional therapy is combined with ongoing low dose prednisone therapy.

\section{RECOMMENDED THERAPY}

Ulcerative colitis: Sulphasalazine remains the drug of choice in patients with mild ulcerative colitis. In moderate disease, combined sulphasalazine and prednisone therapy is recommended. If sulphasalazine is not tolerated or if the patient is known to be intolerant to sulpha drugs, a newer formulation of 5-ASA should be used. In more severe disease hospitalization and aggressive intravenous therapy with adrenocorticotropic hormone or hydrocortisone is indicated. Myers et al (7) showed that in patients who have not received steroids, adrenocorticotropic hormone was the more effective agent, but in patients previously exposed to steroids, hydrocortisone was the drug of

\section{REFERENCES}

1. Belli DC, Seidman E, Bouthillier L, et al. Chronic intermittent elemental diet improves growth failure in children with Crohn's disease. Gastroenterology 1988;94:603-10.

2. Clark ML. Role of nutrition in inflammatory bowel disease: An overview. Gut 1986;27:72-5.

3. Duffy LF, Daum F, Fisher SE, et al. Peripheral neuropathy in Crohn's disease patients treated with metronidazole. Gastroenterology 1985;88:681-4.

4. Hawkey CJ, Hawthorne AB. Medical choice. In patients with limited distal colitis, 5-ASA or hydrocortisone enemas are effective for inducing remission (9). All patients with ulcerative colitis should be on long term maintenance therapy, if at all possible, with some form of 5-ASA.

Crohn's disease: In Crohn's disease the drug of choice is prednisone. Combination therapy with prednisone and 5 . ASA has not been demonstrated to be more effective than prednisone alone. With the development of new delivery systems for 5-ASA there is the potential that these newer agents will be effective in small bowel Crohn's disease. The role for these agents is not clear at this time, but hopefully they will prove to be effective. In severe unremitting disease hospitalization and nutritional therapy are frequently required. Unfortunately, many patients with Crohn's disease are steroid-dependent. Approximately $60 \%$ of patients with Crohn's disease require long term steroid therapy to control symptoms. As indicated, in these patients and in patients with growth failure and delayed puberty, nutritional therapy has proven to be a helpful adjunct.

\section{SURGERY}

Surgery is indicated in patients with ulcerative colitis who have fulminating life threatening disease, those who have responded poorly to treatment, and those in whom the disease has been present for greater than 10 years or in whom there is evidence of mucosal dysplasia. Because of the high incidence of colonic cancer and the variability in

treatment of ulcerative colitis. Gut 1988;29:1298-303.

5. Hodgson HJ. Assessment of drug therapy in inflammatory bowel disease. $\mathrm{Br}$ J Clin Pharmacol 1982;14:159-70.

6. Meyers S, Sachar DB, Present DH, Janowitz HD. Olsalazine sodium in the treatment of ulcerative colitis among patients intolerance of sulfasalazine, a prospective randomized, placebo-controlled double-blind, dose-ranging clinical trial. Gastroenterology 1987; 93:1255-62.

7. Myers S, Sachar DB, Goldberg JD, the development of mucosal dysplasia, surveillance programs are not appropriate in patients with onset of ulcerative colitis in the pediatric age group.

The use of surgery in Crohn's disease is less well defined. One has little choice but surgery in patients with mas. sive hemorrhage, intestinal obstruction due to stricture and extraintestinal fistula formation. The other common rea. son for surgical intervention in Crohn's disease in children is failure of medical therapy with growth failure and delayed puberty. However nutritional therapy should be tried first in these patients. One must remember that cur. rent data indicate that virtually $100 \%$ of patients with Crohn's disease who are operated on will eventually relapse, and many will require further surgery.

\section{CONCLUSIONS}

In summary, the majority of pediatric patients with IBD are adequately controlled with medical therapy and lead normal lives. The course, however, tends to vary consid. erably in the two conditions. Ulcerar tive colitis is usually remitting but can be chronic and continuous. Occasionally it is fulminating and requires emergency colectomy. Crohn's disease can also be acute and remittent but tends to be chronic and unremitting with interspaced acute episodes. In general, patients with ulcerative colitis do fairly well with medical therapy in the early stages, while patients with Crohn's disease have a more chronic continuous course.

Janowitz HD. Corticotropin versus hydrocortisone in the intravenous treatment of ulcerative colitis. A prospective, randomized, double-blind clinical trial. Gastroenterology 1983;85:351-7.

8. Peppercorn MA. Advances in drug therapy for inflammatory bowel disease. Ann Intern Med 1990;112:50-60.

9. Sutherland LR, Martin F, Greer S, et al. 5-Aminosalicylic acid enema in the treatment of distal ulcerative colitis, proctosigmoiditis, and proctitis. Gastroenterology 1987;92:1894-8. 


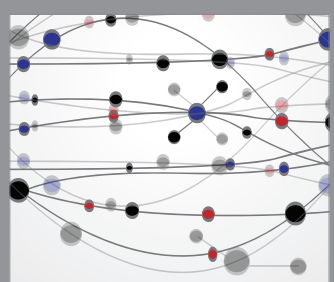

The Scientific World Journal
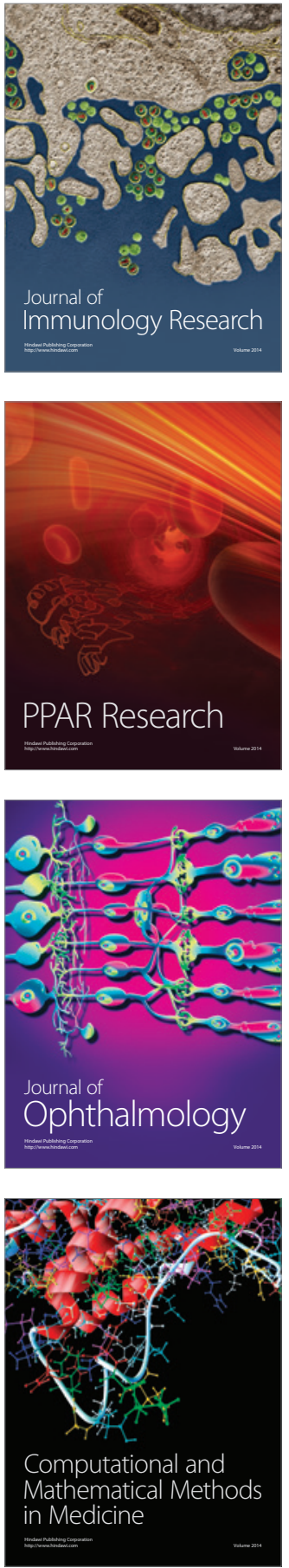

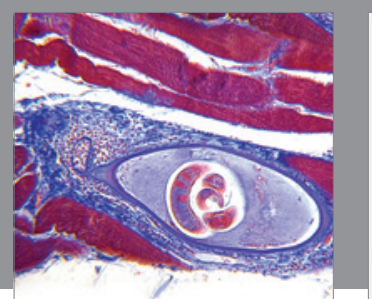

Gastroenterology Research and Practice

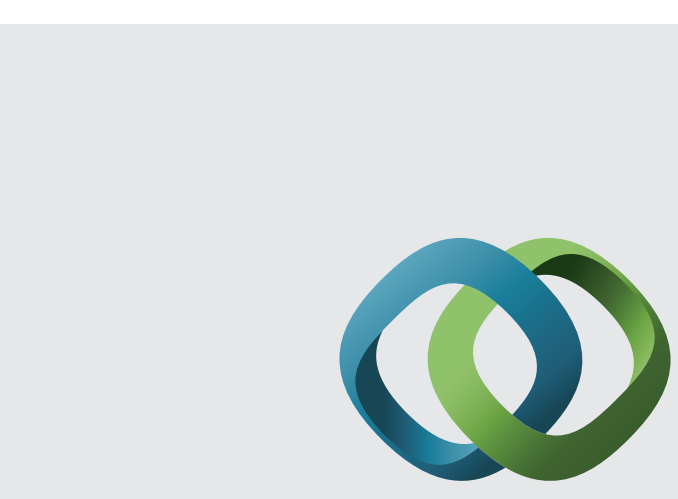

\section{Hindawi}

Submit your manuscripts at

http://www.hindawi.com
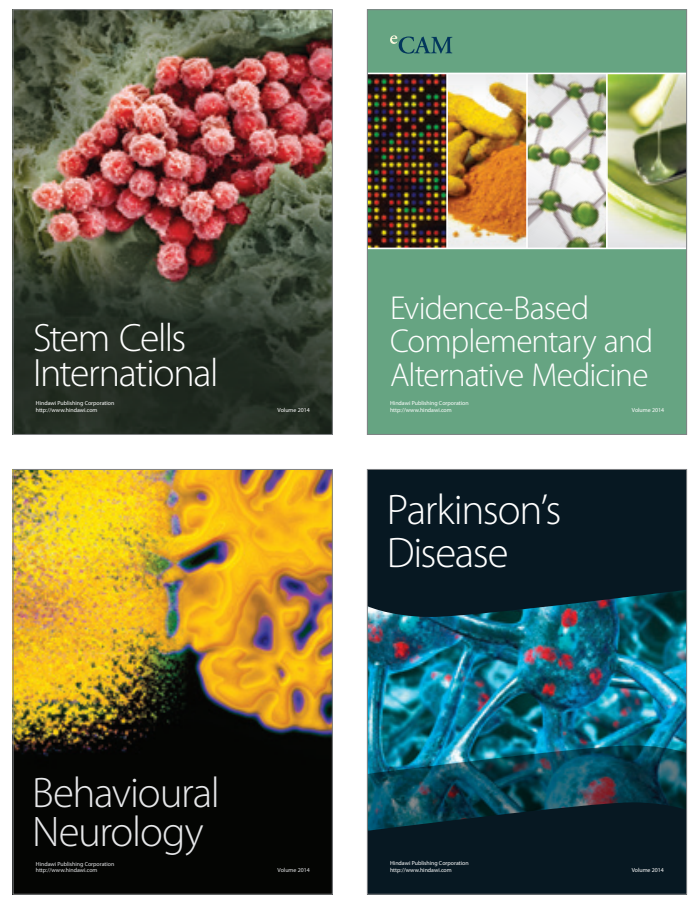
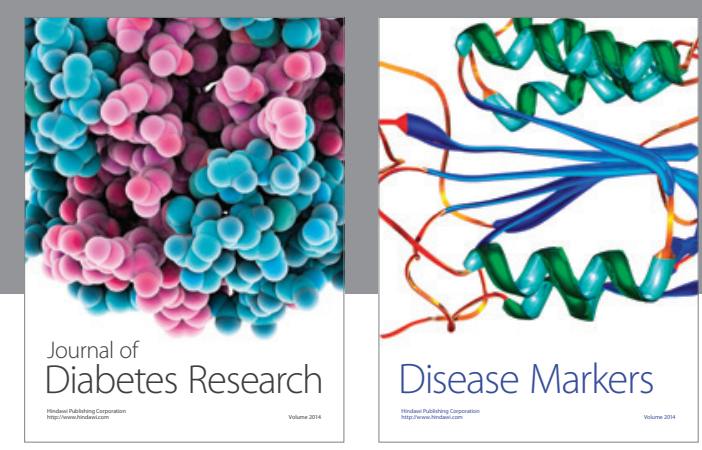

Disease Markers
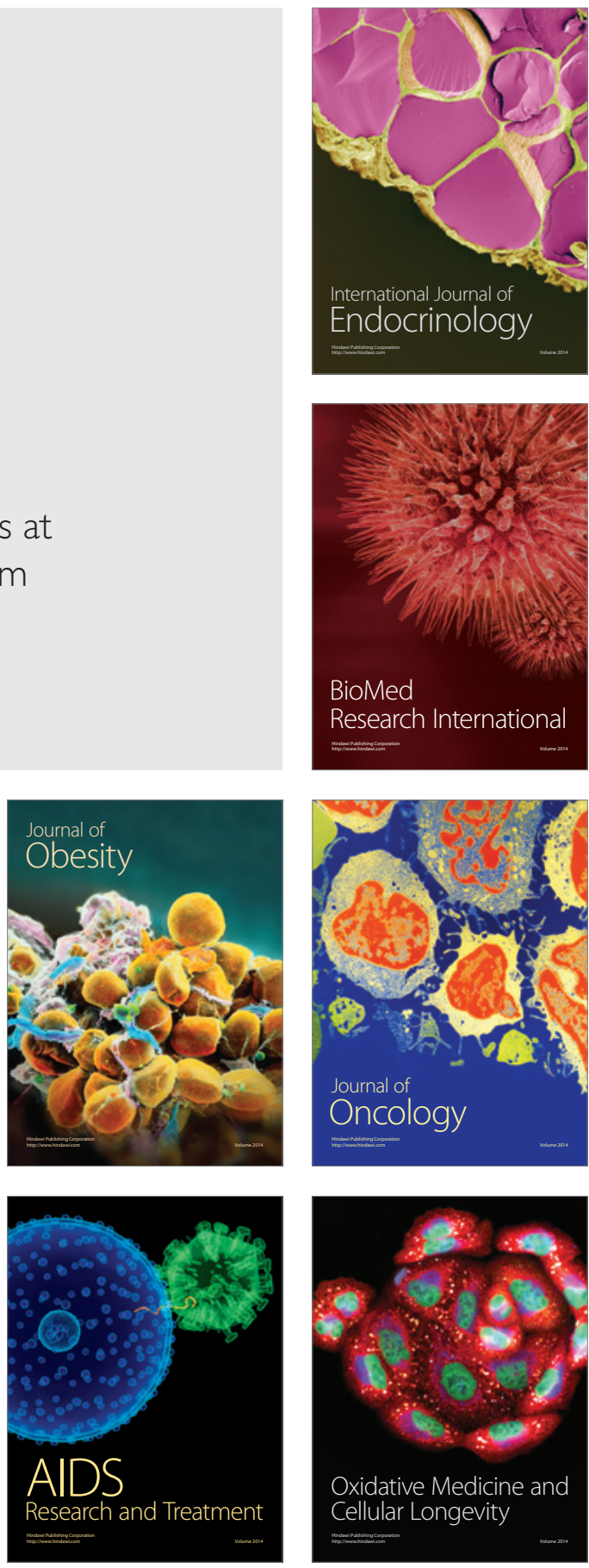